\title{
BEHAVIOR AND ASSESSMENT OF MASSIVE STRUCTURES: AN OVERVIEW OF THE FRENCH RESEARCH PROGRAMS CEOS.fr AND VeRCoRs
}

\author{
J. MAZARS ${ }^{*}$, P. LABBE ${ }^{\dagger}$ AND B. MASSON ${ }^{\dagger \dagger}$ \\ Grenoble University of Technology, France \\ e-mail: jacky.mazars@3sr-grenoble.fr \\ ${ }^{\dagger} \mathrm{EDF}$ \\ Paris, France \\ e-mail: pierre.labbe@edf.fr \\ ${ }^{\dagger}$ EDF-SEPTEN \\ Lyon, France \\ e-mail: benoit.masson@edf.fr
}

Key words: massive structures, THM effects, cracking, aging, sustainability, leakage toughness

\begin{abstract}
Main results of two major research French programs on the study of the behavior of massive structures are presented. CEOS.fr includes three working areas that relate to the control for cracking: THM behavior, monotonic loadings and cyclic loading, including experiments and modeling on large specimens. VeRCoRs is a research program organized around tests performed on a mock-up of a reactor containment building at scale 1/3. A lot of measurements are collected since pouring of concrete and predictive calculations were made in the framework of an international benchmark. Some of these results are presented in this paper.
\end{abstract}

\section{INTRODUCTION}

Beyond stability and strengthening capacity, most concrete structures have to fulfil a number of additional functions, which involve behavioral requirements for reinforced concrete cracking, deformability, water and air leak-tightness and sustainability.

However, the standard rules (EC2, Code Model,...) do not fully address the case of massive elements, for which Thermo-HydroMechanical (THM) effects, scale effects and structural effects induce specific response and preliminary cracking. Furthermore, for massive slabs, walls and containment, shrinkage and creep are prevalent at an early and long-term age.

To address these concerns, the French civil engineering community decided in 2008 to launch a national research project, CEOS.fr [1], with the aim of making a significant step forward in engineering capabilities for predicting the expected crack pattern of special structures under anticipated in-service or extreme conditions. Experiments on large specimen (monotonic, cyclic and THM loadings) and related modelling were performed in order to improve engineering design practices.

In the wake of CEOS.fr, and in view of addressing aging issue for reactor concrete containment, EDF launch in 2013 the VeRCorRs program [2]. A 1/3 scale mock-up was built for this purpose at EDF-Lab Les Renardières, near Paris.

The main objectives of the program are to study: 
- the structural behavior at early age and when aging,

- the aging effects on leak tightness,

- the behavior under severe accident conditions for which the thermomechanical loading is maintained for several days.

\section{CEOS.fr PROGRAM}

CEOS.fr general objective is to make a significant step forward in the engineering capabilities for assessing crack patterns of concrete structures and predicting the expected patterns under anticipated design conditions.

\subsection{General overview}

CEOS.fr program includes three working areas that relate for control of cracking:

- Monotonic loads: the purpose is to calibrate available methods for predicting crack pattern and related strains in tensile or bending conditions;

- Thermo-Hydro-Mechanical behavior (THM): the purpose is to account for the effects on cracking of strains induced by early age behavior, shrinkage and consequences of long-term drying, with due consideration to boundary conditions;

- Seismic and cyclic loads: the purpose is to discuss the seismically induced crack pattern in shear walls, either during or after the event, taking into account the cumulative damaging effect of load cycles.

The three above areas were studied according to the three following approaches, $\mathrm{i} /$ testing, ii/modelling and iii/engineering.

\subsubsection{Testing}

Few experimental results related to large or massive structures are available in the literature; it was then decided to implement tests on large scale specimens with well identified boundary conditions and accurate crack pattern monitoring.

In that framework, four types of specific tests were performed [3]. All test specimens were comprehensively monitored in order to locate and follow crack propagation and measure crack spacing and crack width. Digital Image Correlation (DIC) was especially used to measure crack location and opening on the whole surface of the test specimens.

\section{Tests on large prismatic free strain blocks}

Seven full-scale blocks, such as presented in Figure $1(6.10 \mathrm{~m} \times 1.60 \mathrm{~m} \times 0.80 \mathrm{~m})$ designated RL1 to RL7, has being tested. Two identical reference blocks RL1 and RL6 were made of C50/60 concrete class and 16 HA 32 reinforcing bars. The other individual blocks were made by changing only one feature compared to the reference blocks: concrete grade, concrete cover, reinforcing bar diameter or reinforcement ratio. The average reinforcement ratio was around $1 \%$, which is representative of such structures.

After being casted, the seven blocks matured freely for at least four weeks slightly protected from major weather influence. Afterwards, each block was moved onto the testing bench and submitted to a 4 point bending monotonic loading (Figures 1 and 4). Tests were performed up to $2500 \mathrm{kN}$ to insure that the cracking pattern was completely stabilized.

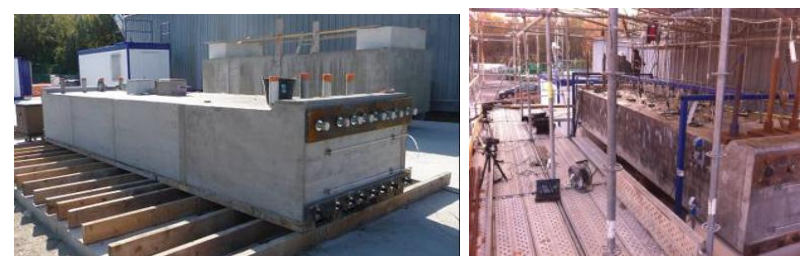

Figure 1: Specimen RL type before and during testing.

Blocks subjected to restrained shrinkage

Three blocks (RG8, RG9 and RG10) have being design in order to restrain shrinkage at early age. Made with the same concrete (C50/60), RG8 is the reference, RG10 included an increase of the cover $(5 \mathrm{~cm}$ instead of $3 \mathrm{~cm}$ ) and RG9 a decrease of reinforcement ratio $(0.56 \%$ instead of $2 \%)$.

The RG specimens are composed of three parts (Figure 2):

- A central block $(6 \mathrm{~m} \times 0.50 \mathrm{~m} \times 0.80 \mathrm{~m})$, which constitutes the test specimen;

- Two heads (0,9 m x 2,2 m x 0,9m);

- Two steel struts, which restrain strain in order to induce cracks in the specimen. 


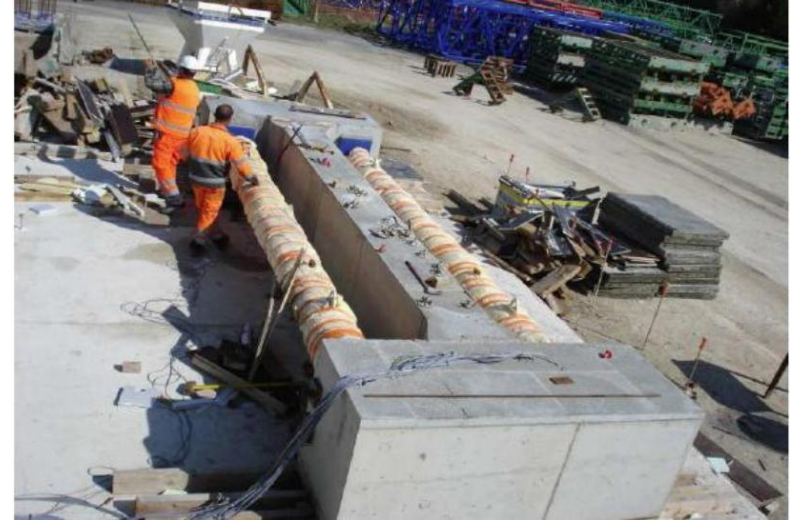

Figure 2: RG specimen and struts to restrain shrinkage.

Tests on 1/3 scale shear walls

This part of the program has been established in order to deepen the phenomenon of cracking during and after an earthquake. The design of the related test specimens was driven by two conditions:

- To accurately reproduce reinforced thick shear walls representative of industrial structures;

- To adapt the availability of the testing means, the capacity of jacks of the testing bench being limited to $4500 \mathrm{kN}$.

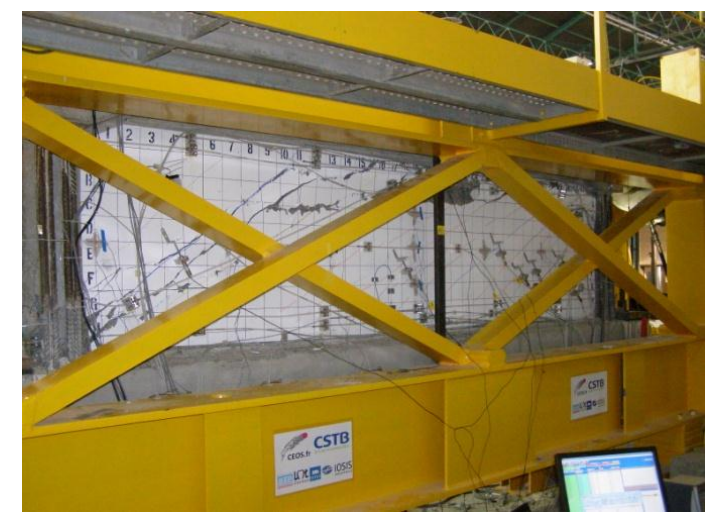

Figure 3: Shear wall specimen in its frame, during testing.

This led to the choice of four shears walls, 1/3 scale (height $=1.05 \mathrm{~m}$, length $=4.2 \mathrm{~m}$, thickness $=0.15 \mathrm{~m})$ designated SHW1 to SHW4. The walls differ from each other either by the type of concrete or the reinforcement mesh. For test the walls were put inside a frame, embedded at their base (Figure 3). Two pistons were fixed on each side in order to apply a horizontal loading at the top of the wall (see Figure 13).

The shear walls were tested beyond the Ultimate Limit Stage (ULS), up to failure.
Three of them were subjected to horizontal alternate loading applied in series of three cycles with a $\pm 300 \mathrm{kN}$ increasing step. The SHW3 specimen was tested under nonalternate loading.

\section{Additional tests}

In addition of tests on full scale blocks (RL) and in order to analyse scale effects, experiment on six $1 / 3$ scale blocks $(1.90 \mathrm{~m} \mathrm{x}$ $0.25 \mathrm{~m} \mathrm{x} 0.44 \mathrm{~m}$ ) have being performed.

Furthermore, in order to complete cracking analysis, particularly with respect to the variability of their spacing and openings, nine large ties, has been tested with various sizes and types of reinforcement.

\subsubsection{Modelling and simulations}

Much has been invested on models and modelling. Different actions helped initially to test existing models and in a second phase to consolidate these models or to develop new models in order to make them operational to help the analysis of the conducted experiments [4]. Finally in addition to these "physical" experiments, models developed were used to carry out a program of "numerical" experiments, all providing a solid database to allow engineering to move forward on its proposals for standards.

\section{Benchmarks and workshops}

Thanks to an internal benchmark and a first workshop (Concrack1) organised in December 2009 in order to open up new relations and exchanges with the international community, the existing models and their performances were tested and compared to test results from existing experiments. As a conclusion of the workshop, it was decided, based on the experiment derived from CEOS.fr project, to organise an international benchmark dealing with the modelling of the behavior of the tested mock-ups and large bodies. A restitution workshop - ConCrack2 - has been organised in June 2011 and the main results have been published in a special issue of the EJECE journal [5]. In the same line, thanks to a coorganisation France - Japan, a further 
workshop was held on THM effects ConCrack 3 (March 2012).

MEFISTO research program

In parallel to CEOS.fr, the French National Research Agency (ANR) launched the MEFISTO research project in 2008. As a result of the collaboration between the researcher teams of MEFISTO and CEOS.fr projects, it was possible to develop models, which consider the following topics and approaches:

- Modelling of effects under monotonic loading in connection with the global performance of the material (stress-strain model) and the local damage process (trajectory and width of cracks);

- Modelling of THM coupled effects on concrete at an early age and assessment of induced stresses and local damage.

To improve the prediction of cracking in structures, two major ways are considered:

- Continuous methods based on the use of constitutive equations related mainly on the concrete damage/plasticity theories that do not describe a crack in a discrete manner but rather represent a damaged area [6]. The objective is to use all information available to represent the position of macro-cracks and crack openings in post processing tool for finite elements simulations (2D or 3D) but also for approaches called simplified, such as multi-fiber beams (based on 1D models).

\section{- Discrete and mixed methods}

To get cracking at the centre of the simulation discrete approaches or a joint use of continuous and discrete approaches have been developed [7]. In addition to these two approaches, special attention is paid to the consideration of uncertainty in predicting the opening and spacing of cracks. Reliabilitytools were developed to be coupled with mechanical models.

\section{Numerical experiments}

The numerical simulations carried out show that the models are able to adequately represent the behavior of the tested specimens (static, cyclic and thermo-hygro-mechanical loadings). It was then decided to use these models to extend the experimental program through numerical experiments.

In this framework it was planned a numerical simulation program to supplement the results obtained in physical experimentations by analysing the effects of various parameters on cracking.

In particular have been studied the effects of the geometry, of the concrete cover, of the amount of reinforcement, of the strength of concrete, ...etc.

\subsubsection{Engineering}

The objective of that part of the program was to develop design rules from test results and numerical simulations with the aim of establishing guidelines for the control of cracking phenomena. This was made possible thanks to many results from experiments and modelling conducted throughout the program and with reference to existing engineering rules from standards (EC2, MC 2010 [20]).

In March 2014, a final workshop - Concrack4, co-sponsored by the European Joint Research Centre, was organised in Ispra (Italy). The main results obtained during CEOS.fr program and related works in Europe were presented and based on these results, standard rules for reinforced concrete were discussed with a panel of international experts. As a conclusion, it was decided to issue the Guidelines for the control of cracking phenomena [8].

\subsection{Some important results}

The results achieved during the six years of the research program are many. We propose in the following to focus on some examples highlighting the specific problems inherent to cracking of massive elements.

\subsubsection{Cracking due to monotonic loading}

Two identical reference "free strain" blocks RL1 and RL6 were made of C50/60 concrete class and 16 HA 32 reinforcing bars as longitudinal reinforcement (Figure 5). After concrete maturation, the beam is fixed onto the testing bench thanks to 4 prestressing bars crossing the testing bench and also the beam itself (Figure 4). It is submitted to a monotonic 
loading by two row of $4 \times 1 \mathrm{GN}$ jacks spaced of $1.6 \mathrm{~m}$ below the central part of the beam. Loading is performed till $2500 \mathrm{kN}$ to insure that cracking pattern is completely stabilized for each specimen (Figure 4).

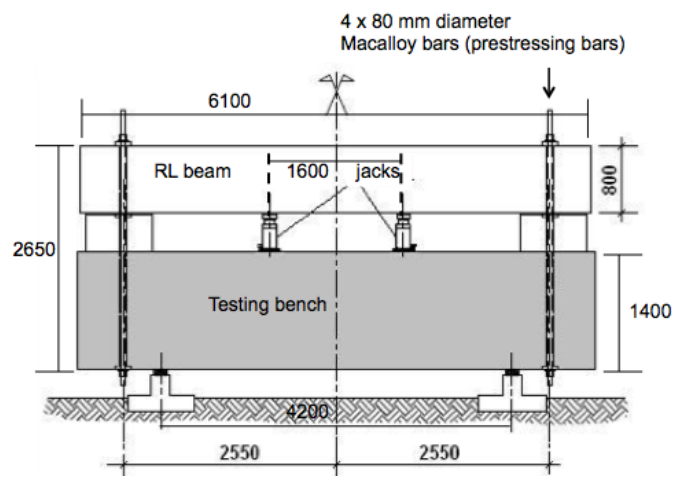

Figure 4: Specification and principle of bending test for RL specimens.

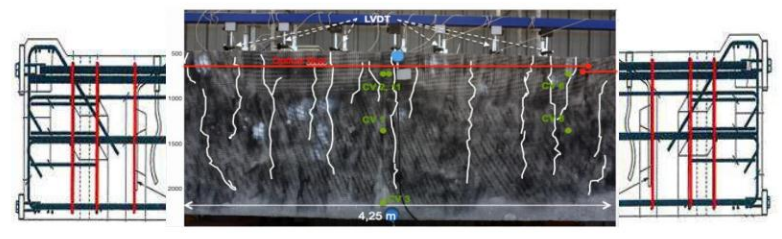

Figure 5: Rebar mesh and cracking pattern from DIC analysis [3].

In contrast to $\mathrm{RG}$ beams (restrained shrinkage), the RL blocks are said at "free shrinkage". That said, one of the objectives was to observe whether the effects of the maturation of concrete had an influence on the mechanical behavior of massive elements. Figure 5 gives, superposed on the reinforcement scheme, the crack pattern in the central part of the beam, from a digital correlation analysis (DIC).

In that framework the Figure 6 gives an idea of the variety of measures that have been made on this test. From top to bottom we note:

- The temperature evolution inside the beam showing at removal framework a gradient of about $5^{\circ} \mathrm{C}$ between core and the upper surface;

- The evolution of strain inside the beam which highlights, after 2 days, a field of shrinkage inside the whole beam (about $80 \mu \mathrm{m} / \mathrm{m}$ ), which demonstrate a quasihomogeneous response of the section of the element. It was observed on other specimens that, when cracks developed inside the beam, the shrinkage field is not homogeneous (it can be the case if the sample is not protected from a very low external temperature).
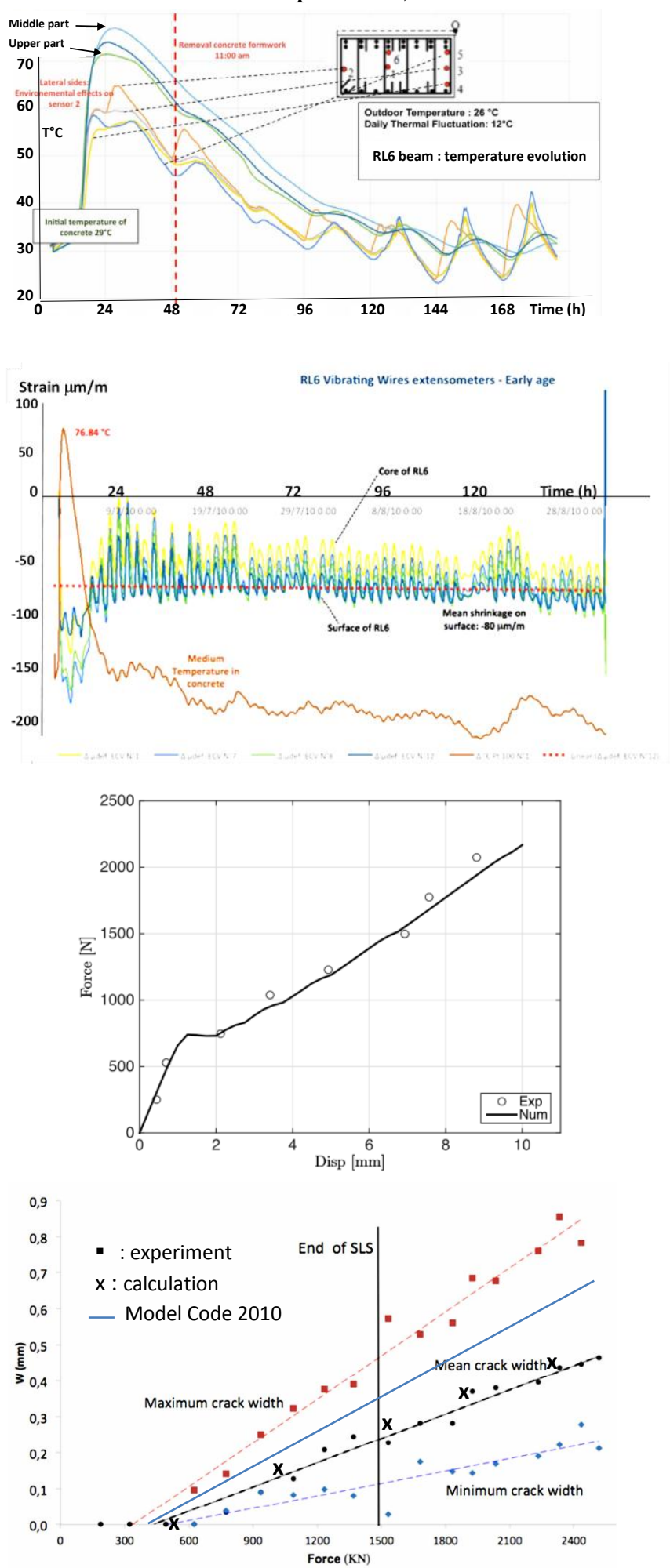

Figure 6: RL6 beam, from top to bottom: Inside temperature evolution- Inside strain field at early age Force-displacement evolution (calc./exp. [9]) - Crack width vs load (calc./exp. [10]). 
- Considering a reference state without cracks, different types of calculations were performed (1D-2D-3D). The one presented here is based on enriched multi-fiber beam with a concrete damage model [9] which leads to a very good simulation of the force-displacement behavior;

- From DIC measurements, were obtained in the central zone (at constant flexure moment) extensive information on cracking. The average spacing of cracks is $0.21 \mathrm{~m}$ (lower than that given by the construction codes \# 0.30m). From this data, the same simulation as before gives an average opening quite comparable (see [10] for details).

\subsubsection{T. H.C.M. and cracking}

As shown above on RL blocks, due to hydration effects, the evolution of temperature and shrinkage, are substantial in massive elements. The purpose here is to show how this rise, in a situation where the shrinkage is restrained, promotes the creation of cracks prior to any mechanical loading. The structures tested are with a special form chosen to use two metallic struts in order to restrain the contraction of the central part and consequently provoke cracking at early age (Figure 7).
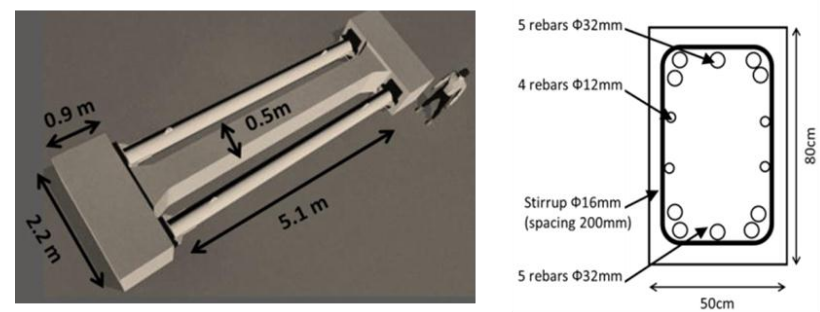

Figure 7: Test and reinforcement of specimen RG8.

Three different structures with different rebar ratio and cover have being designed (RG8, RG9 and RG10). All specimens were fully instrumented ( 9 internal temperature sensors, 24 vibrating cords, 3 internal optical fibers, 12 strain gages on rebars,... see [3] for details). The external temperature, the solar radiation and the exposition of the specimen were also measured during the test.

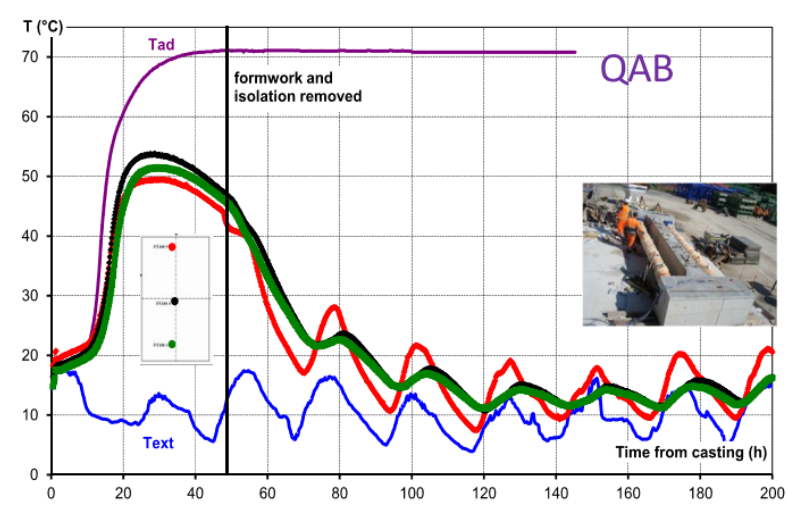

Figure 8: Temperature at three location of the RG8 specimen (QAB: temperature in an adiabatic test).

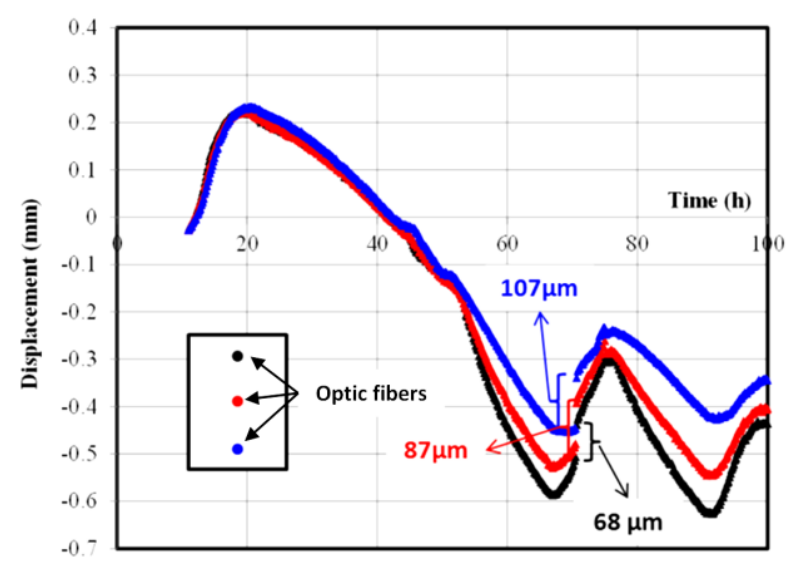

Figure 9: First cracking measured by optic fibers.

Figure 8, gives for three locations inside the specimen the temperature history, compare to the one in quasi-adiabatic conditions (QAB) and to the exterior temperature evolution (Text). The optical fibers make possible the detection, in time and location, the appearance of cracks (Figure 9). On the specimen RG8 the first crack appeared at $72 \mathrm{~h}$, in the central part of the beam. The Figure 9 shows that this crack is more open in the lower part of the beam than on the upper part (concomitant effect of gravity).

The results from a THCM model [11] are presented herafter. This model, the principle of which is given Figure 10, is able to reproduce the hydration of composed binders and its consequence for in-situ conditions. Indeed it is based on the coupling between hydration, water content and temperature. Hydration is managed by kinetic equation while water content and temperature are managed by balance equations. The coupling is made first 
by the fact that the hydration consumes water and produces heat but also the fact that the variation of water content and temperature will affect the kinetic.

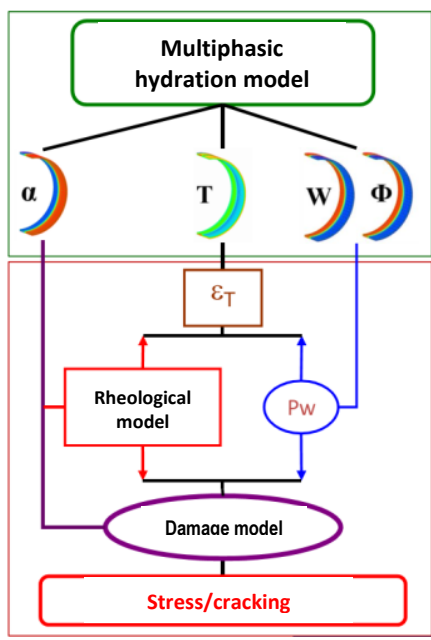

$\alpha=$ hydration degree

$\mathbf{T}=$ temperature

$\mathbf{W}=$ water content

$\Phi=$ porosity of the

paste

$\varepsilon_{\mathrm{t}}=$ thermal strain

$p_{w}=$ capillary, $f(w, \Phi, T)$

Figure 10: Principle of the THCM model [11].

In order to evaluate the induced stress, a rheological model which reproduces the viscoelastic behavior of concrete at early age is used. The model is divided in 3 levels, $\mathrm{i} / \mathrm{an}$ elastic one for the instataneous behavior, ii/a visco-elastic level for the reversible part of the creep and, iii/a non-linear viscous level for the irreversible part of the creep. Next, the consequence of the consumption by hydration of water is the autogeneous shrinkage. All the mechanical properties are expressed according to hydration degree development and a specific damage model [12] is then activated to finally deduced stress and cracking. The number of parameters involved needs to perform several sample tests (semi-adiabatic, creep, shrinkage, thermal and hygral properties, fracture energy,...).

Figure 11 gives the results obtained for the temperature evolution in the core and on the upper surface of the beam. These very good results were made possible thanks to the efficiency of the model and the parameters calibration, but also to the good description of the boundary conditions. On Figure 12 are given the successive appearance of cracks with time; RG8 is on the middle line, time of appearance is close to the experimental one (60h instead of 72h). Figure 12 gives also the result of a parametric study: the number of transverse cracks increases with the increase of the cover $(5 \mathrm{~cm}$ instead of $3 \mathrm{~cm})$ and decreases with the decrease of the reinforcement ratio $(0.56 \%$ instead of $2 \%)$.
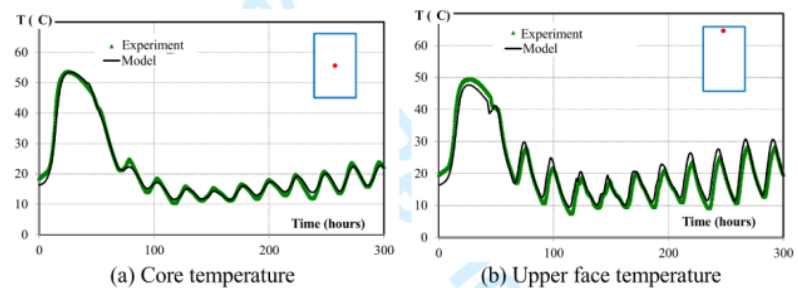

Figure 11: temperature modelling [4].

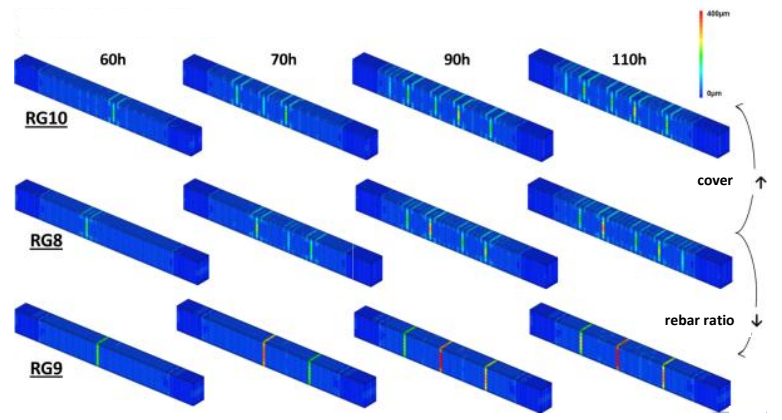

Figure 12: Cracking dependency from age, cover size and rebar ratio [4].

\subsubsection{Squat shear wall under monotonic and cyclic loading}

Four tests have being performed (principle given Figure13). One monotonic (SHW3), one cyclic with a concrete at low strength (SHW1, C25 instead of C40) and one cyclic with a different reinforcement mesh (same ratio but lower diameters, SHW4 $\Phi=8 \mathrm{~mm}$ instead of $\Phi=10 \mathrm{~mm}$ ), [3]. Figure 14 gives the envelope of force-displacement curves for the four tests.

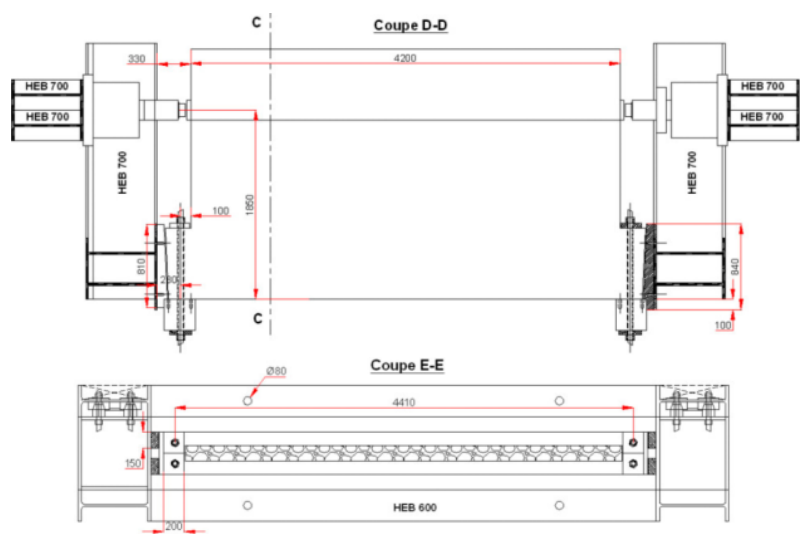

Figure 13: Principle of the shear wall test [3].

Many simulations were conducted on these tests; particularly in the framework of the benchmark ConCrack cited section 2.1.2. 


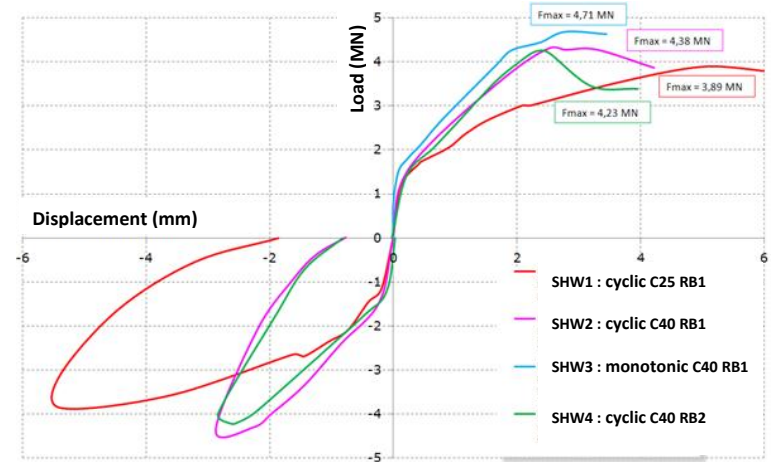

Figure 14: Envelope force-displacement curves for the four tests [3].

They used conventional numerical techniques (FE 2D or 3D), but also simplified methods (equivalent lattice model) and even discrete element methods. Some of this work can be found in [5].

We chose to show here a particularly effective result obtained by Yamamoto et al. [13] that use à discrete elements method (DEM). Figure 14 gives the principle of the method and the mesh used for both, concrete and reinforcement. The model used here is very complete. Each rigid particle has three translational and three rotational degrees of freedom, the boundary surface of two particles is divided into several triangles and two shear springs are set at their center (Figure 15). A constitutive model for concrete gives tension, compression and shear curves. Reinforcement is modeled as a series of regular beam elements that can be freely locate within the structure [14]. There are attached to the concrete particles by means of zero-size link elements that provide a load-transfer mechanism which allows the description of rebar-concrete bond.
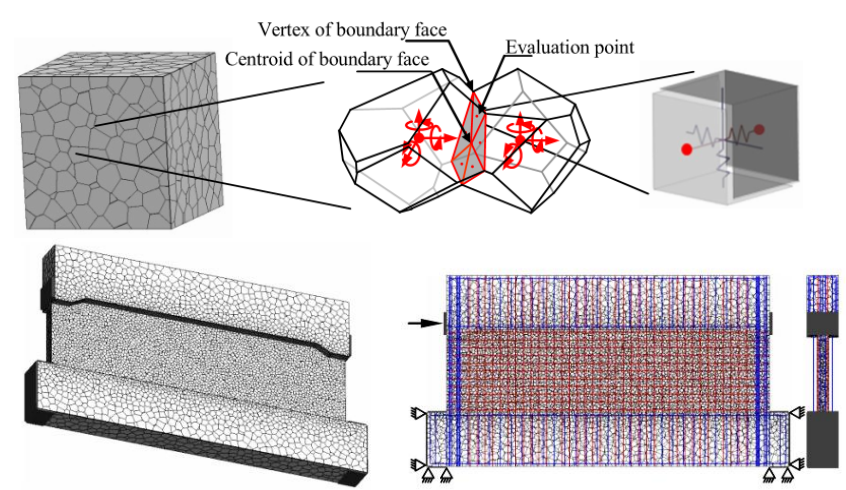

Figure 15: Mesh and reinforcement scheme for a Discrete Element Method (Yamamoto et al. [13]).
Calibration of the model need to reproduce, with DEM, tests on sample which gives the principal characteristics of the materials (concrete and steel).

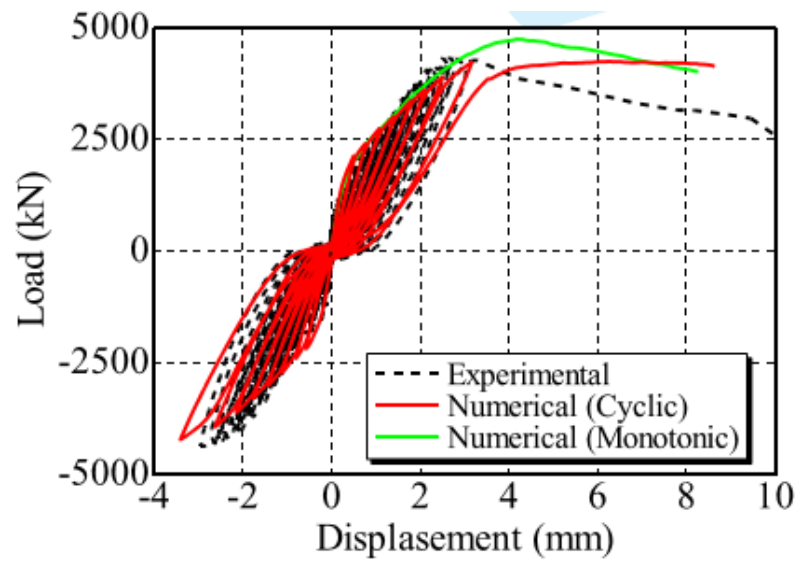

Figure 16: DEM results for SHW2 (monotonic) and SHW3 (cyclic) [13].

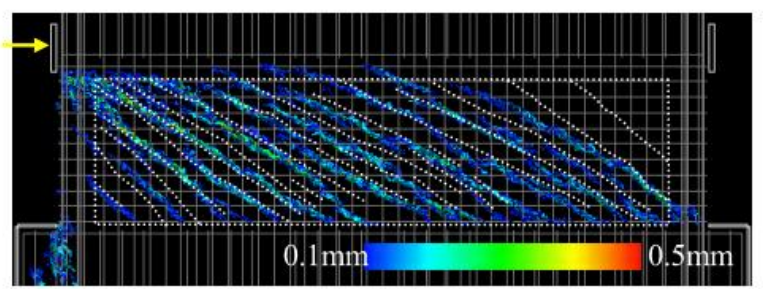

Figure 17: Crack pattern for SHW2 at 4.2MN (experiment: dash line - calculation: blue line) [13].

The results of the simulation are given Figure 16 for the force-displacement behavior for both, monotonic and cyclic loading and Figure 17 gives the crack pattern, for the monotonic case, at $4200 \mathrm{kN}$ (close to the maximum load). The comparison with experimental results appears very good, but the price to pay is an important computer time.

\section{VERCORS PROGRAM}

As part of EDF's continuous effort on the safety and life extensions to its fleet of nuclear power plants, an experimental mock-up of a reactor containment building at $1 / 3$ scale had been built at Les Renardières, near Paris (Figure 18). This mock-up is completed since end 2015. It is finely instrumented so that its behavior is monitored from the beginning of the construction. More than 500 sensors and 2 $\mathrm{km}$ of fiber optic cables are positioned in the concrete and both on the rebar and on the prestressing cables. During the construction, 
measurements were achieved just after concreting during time intervals of one hour. During the construction, measurements were achieved just after concreting during time intervals of one hour. During the research program, several measurements are collected every day on each sensor. Figure 19 gives a global view of the whole VeRCoRs facilities. Hundreds of samples of concrete have been prepared and tested to determine material properties and behavioral parameters, including modulii and strength, drying, shrinkage, creep, permeability...etc.

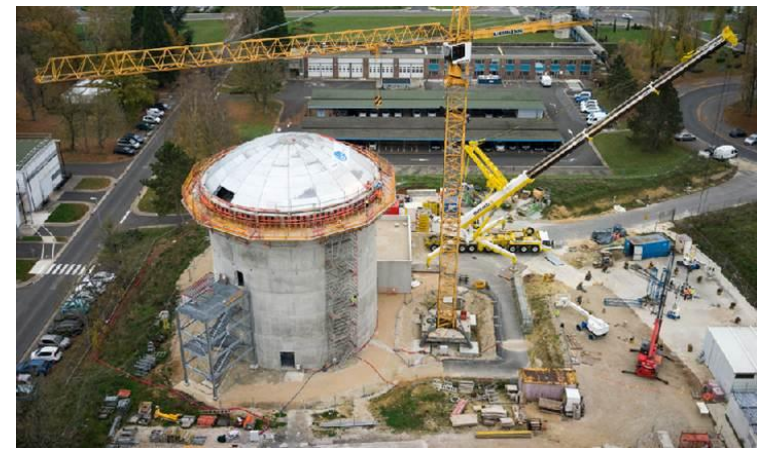

Figure 18: The VeRCoRs containment building under construction.

The experimental campaign consists in a daily measurement (four measurements per day) of the whole sensors and in a periodic air pressure test of the mockup, every year. During this test, the containment is pressurized at 5.2bar absolute (pressurization at 200 $\mathrm{mbar} / \mathrm{h}$ and plateau at $5.2 \mathrm{bar}$ absolute during 24 hours before deflation at $150 \mathrm{mbar} / \mathrm{h}$ ). The whole sensors are interrogated each 30 minutes and the leakage is measured. EDF proposed in 2015 a first benchmark dedicated to early-age, mechanical and leak-tightness behaviors.

\subsection{Benchmark and workshop}

For this first benchmark, three main themes are proposed:

- Theme 1: Early age

Prediction of the gusset behavior at early age, since the pouring to ten month (end of erection of the whole containment). The results expected were temperature, deformations and stresses evolutions and cracking pattern.
- Theme 2: Containment history

Prediction of deformations, stresses and cracking history of the whole containment wall (before/after prestressing, after pressurization test)

- Theme 3: Leakage

Prediction of air leakage (global, dome area, equipment hatch area, gusset area, cylindrical part) at the end of the 5.2bar absolute pressurization plateau.

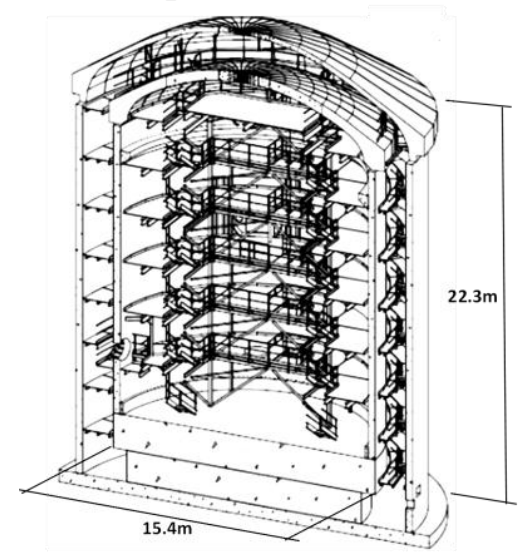

Figure 19: Scheme showing the VeRCoRs facilities.

The benchmark starts 1st January 2015 and ends the 31st of October 2015. Intermediate results, such as modelling description, hypotheses and preliminary calculations have been loaded at the end of April 2015. Experimental data, visual inspections and measurements (deformations), has been provided in December 2015, after the first pressure test of the mockup. A workshop, dedicated to the teams' results presentations and discussions was held 7-9 March 2016.

Two other benchmarks are planned in the future: 1/ In 2017, to assess the impact of two successive identical pressurization tests on the concrete structure and to take into account the aging, especially long term creep and shrinkage and 2/ In 2021, to predict the behavior under severe accident conditions.

\subsection{First series of results}

The Vercors operation is in its beginning, but the first measures have delivered their results. Furthermore, the first benchmark is now complete. In the next few pages we propose, as example, to compare some results of these first 
measures to some simulation results from works in relation with the benchmark. To have more complete information see [15].

\subsubsection{Gusset}

The first theme of the benchmark is on the prediction of the behavior of the gusset from the pouring time to the end of erection of the whole containment. As example, we propose below the results at two particular points of the gusset, highlighting the Thermo-HygroMechanical effects. These points, G2 and F2, are at the base and the outside part of the gusset where are measured, from pouring, temperature and strain (see Figure 20).

These measurements are compared with simulations based on the model (THCM [11]) presented section 2.2.2. The three fitting parameters of the multiphasic hydration model were determined by an inverse analysis on an adiabatic test. The instantaneous characteristics of concrete (strengths, Young's modulus) increase as the material hardens. So the De Schutter's law [16] is adopted to consider the effect of hydration on these mechanical properties. The studied structure corresponds to a radial piece of cylindrical internal containment with angle of $4.5^{\circ}$ which contains pedestal, base slab, gusset and interior wall. It was modelled using a $3 \mathrm{D}$ mesh with 13178 cubic elements. The initial temperature of concrete casted at each stage is considered as the initial condition. The daily variation of external temperature is used directly in our thermal modelling as a convective boundary condition. During the formwork of each stage, the equivalent convective coefficient of the formwork is used and it is evaluated by means of a serial model. After formwork removal, only the free convective coefficient, which is estimated due to wind and given in the project, is used. Considering the equivalent and free convective coefficients for the period of formwork and the external temperature variation, plus the heating condition at gusset, the thermal results of modelling are in good agreement with the experimental measurements (Figure 20, [17] ).

Numerically, for any angular cross-section of the reactor, the responses obtained with the THCM modelling were the same for any point that has the same height and same distance from the wall because of geometrical symmetry of the structure. Therefore, the numerical results (Mod. Fext. in Figure 21) were successfully compared with experimental results in terms of concrete strains for points $\mathrm{F} 2$ and $\mathrm{F} 4$.

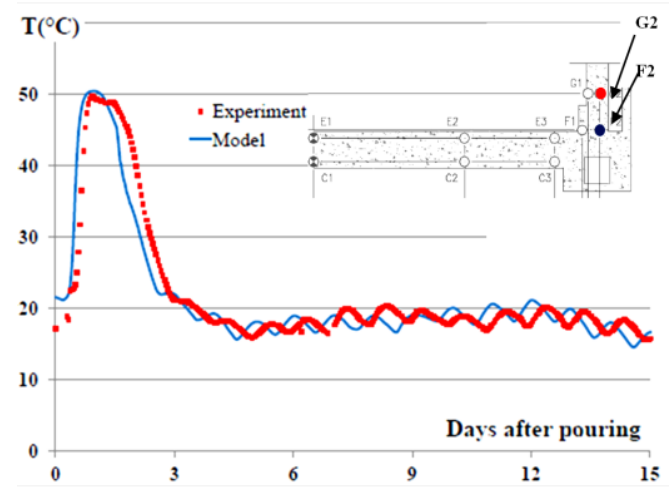

Figure 20: Thermal evolution at location G2 (outer face) for the gusset at early age (from [17]).

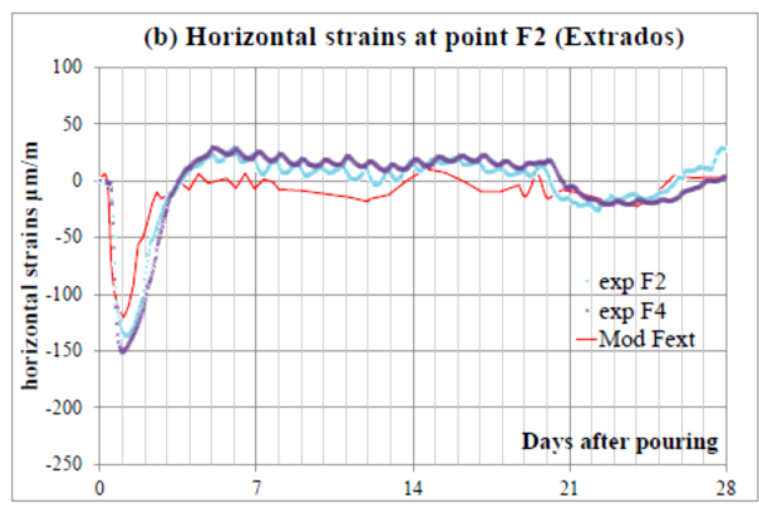

Figure 21: Horizontal strain in the gusset (outer face) for the gusset at early age (from [17]).

\subsubsection{Cylinder part of the containment}

The second theme of the benchmark is on the prediction of the strain and stress states, and the cracking history of the whole containment wall. The idea of this part is to follow the various developments that affect the structure since its construction. The effects of prestressing, aging and the first pressurization test must be taken into account. The point measurements are the same on the gusset as the previous theme and Figure 22 gives those in relation to the wall of the containment. $\mathrm{H} 1$ is on the outer part and $\mathrm{H} 2$ on the inner part.

For the benchmark, the mesh of the whole containment was given to the participants (Figure 22) and a large data base on the main 
characteristics of the materials used is available. As example, we have chosen to present some of the results provided by one of the benchmark participant [18].

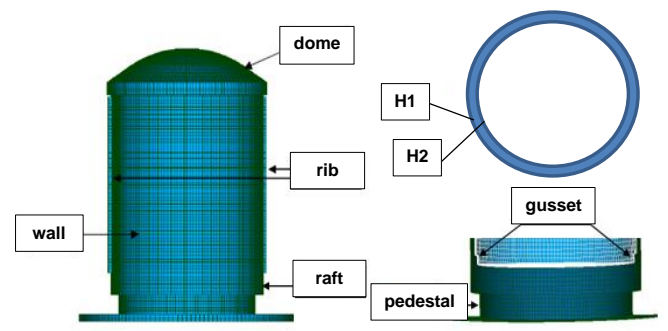

Figure 22: F.E. mesh and (H1, H2) location of strain sensors in the current part of the wall.

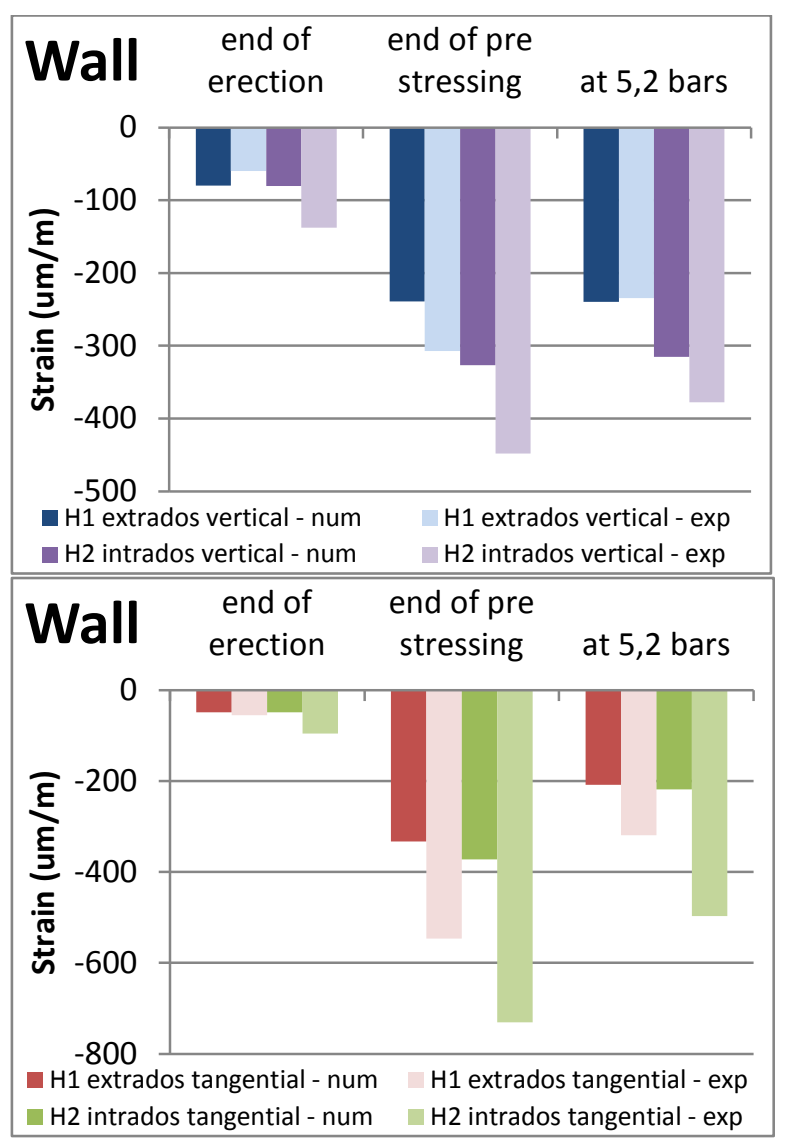

Figure 21: Horizontal and tangentiel strain at location $\mathrm{H} 1$ (intrados) and $\mathrm{H} 2$ (extrados) at different times.

Code_Aster ${ }^{\circledR}$ and a full 3D finite elements model of the VERCORS mock-up are used for calculation. The delayed behavior of concrete includes basic creep and drying creep as described in [19]. Are used, i/ a rheological model (Burger model) for basic creep and ii/ a classical viscosity model (driven by the relative humidity variation) for drying creep. Before dealing with the two phenomena, chained thermo-hydric calculations are performed in order to obtain the temperature and the water content evolution in the structure. In order to control time consuming, no coupling with damage is introduced, however a post-process analysis, based on the local tensile stress values, is performed to estimate crack openings using the CEB-FIP formula [21]. The VeRCoRs mock-up behavior is simulated from the cable tensioning instant until the end of the first pressurization test. The stress and strain values are computed at the location of the various sensors. Figure 21 gives vertical and tangential strain values at $\mathrm{H} 1$ and $\mathrm{H} 2$ location and for different times. They are compared to those measured in situ. Vertical strain appears better simulated as the tangential one.

\subsubsection{Leakeage toughness}

The last theme is the prediction of air leakage during pressurization test. Pressure evolves from 1 to 5.2 bar (absolute) within 21 hours and a plateau follows during $24 \mathrm{~h}$ before a progressive deloading. The first pressurization test gives a global air leakage of $7.7 \mathrm{Nm} 3 / \mathrm{h}$.

In the continuity of the previous calculation, air leakage is estimated accordingly to Darcy and Poiseuille's laws (Table 1). It was assumed that only the cracks induced by prestressing and the pressurization process are activated. High stress concentration in the hatch area led to an important crack opening according to CEB-FIB formula. Hence, the air leakage in this area is certainly overestimated. This is mainly due to the limitation of the creep model which has not been coupled with a damage model. Conversely, for the gusset area, air leakage is mainly due to the basic permeability of concrete, while, in real situation early age cracks reopen [18].

\begin{tabular}{|c|r|r|}
\hline \multirow{2}{*}{ Area } & \multicolumn{2}{|c|}{ Air leakage repartition } \\
\cline { 2 - 3 } & Exp. & \multicolumn{1}{c|}{ Calc. } \\
\hline Total $\left(\mathrm{Nm}^{3} / \mathrm{h}\right)$ & 7.7 & 13.8 \\
\hline gusset & $56 \%$ & $2.5 \%$ \\
\hline hatch area & $15 \%$ & $88 \%$ \\
\hline cylindrical part (wall) & $25 \%$ & $7 \%$ \\
\hline dome & $4 \%$ & $2.5 \%$ \\
\hline
\end{tabular}

Table 1: Leak Tightness during the first air presure test. 


\section{CONCLUSIONS}

Main results of two major research French programs on the study of the behavior of massive structures are presented. CEOS.fr includes three working areas that relate for control of cracking: THM behavior, monotonic loadings and cyclic loading. VeRCoRs is a research program organized around tests performed on a mock-up of a reactor containment building at scale $1 / 3$. It was shown that the behavior of massive structures is particularly influenced by THM effects at early age especially as shrinkage is restrained or prevented. The simulations show that they are able to take these phenomena into account under the condition to correctly handle the parameters identification and the description of the boundary conditions. Applications on the Vercors model demonstrates the interest and the need of seach modeling strategies to be able to predict the evolution of strain and stress states with time and leakage when the containment building is pressurized. Many tests are still to achieve and a call to participate in a new benchmark is coming.

\section{REFERENCES}

[1] http://www.ceosfr.irex.asso.fr/, CEOS.fr final report 2015.

[2] https://fr.amiando.com/EDF-vercorsproject.html, VeRCoRs presentation 2015.

[3] Cortade J., Rospars C., Torrenti J-M., P. Bisch et al., CEOS.fr, synthèse des résultats expérimentaux, Report LP1 2015

[4] Cortade J., Rospars C., Torrenti J-M., P. Bisch et al., CEOS.fr, Modélisation et interprétation, Report LP2, 2015.

[5] Mazars J. editor of "Control of cracking of RC structures: CEOS.fr international benchmark", Europ. J. of Environ. and Civil Eng., special issue, 18(7-8), 2014.

[6] Giry, C. \& Dufour, F. \& Mazars, J. Stressbased nonlocal damage model. Intern. J. of Solids \& Struct., 48(25-26), 3431-3443.

[7] Oliver-Leblond, C. \& Delaplace, A., Ragueneau, F., Richard, B. Nonintrusiveglobal/local analysis for the study of fine cracking. Intern. J. for Num. and Anal. Methods in Geom. 37(8), 973-992.

[8] Labbé P. et al., Guidelines for the control of cracking phenomena, Outcomes of the French Research program CEOS.fr, ISTE London, to be published, 2016.

[9] Mazars J., Hamond F., Grange S., A new 3D damage model for concrete under monotonic, cyclic and dynamic loadings, Mater. and Struct., (2015) 48:3779-3793.

[10] Mazars J., Grange S., Simplified Modeling of Reinforced Concrete Structures for Engineering Issues, Comp. and Concrete, 2015, 16(5) 683-701.

[11] Sellier, A., and Buffo-Lacarrière, L. Towards a simple and unified modelling of basic creep, shrinkage and drying creep of concrete. Europ. J. of Environ. and Civil Eng., 13(10), 1161-1182, 2011.

[12] Sellier, A. et al.. "Orthotropic damage coupled with localized crack reclosure processing. Part I: Constitutive laws." Eng. Fract. Mechanics, 97, 148-167, 2013

[13] Yamamoto, Y., Nakamura et al. Simulation of crack propagation in RC shear wall using a 3D Rigid-Body-Spring model. Europ. J. of Environ. and Civil Eng., 18(7-8) 780-792, 2014.

[14] Bolander, J. E., \& Saito, S. Fracture analysis using spring network with random geometry. Engineering Fracture Mechanics. 61.5-6, 569-591, 1998.

[15] Corbin M. et al., VeRCoRs benchmark report , VeRCoRs workshop, Les Renardières Moret, (France), 2016.

[16] De Schutter G., Taerwe L., Degree of hydration-based description of mechanical properties of early age concrete, Mater. Struct., vol. 29, no. 6, pp. 335-344, 1996.

[17] Chuun P., Buffo-Lacarrière L., Sellier A., Cracking risk prediction of young age behavior, VeRCoRs Work. Moret, 2016.

[18] Bouhjiti E.M., Masson B., Prediction of air leakage rate in nuclear containment structures, VeRCoRs, Work. Moret, 2016.

[19] Code_Aster, version 13, EDF R\&D http://www.code-aster.org.

[20] MC2010, fib Model Code for concrete structures 2010 - Ernst \& Sohn, Berlin 2013. 